\title{
Congenital hydrocephalus as a rare cause of severe type 1 plasminogene deficiency
}

\author{
Ali Annagür1, Hüseyin Altunhan2, Orhan Özbek3 ${ }^{3}$ Banu Turgut Öztürk4, Rahmi Örs5 \\ ${ }^{1}$ Selçuk University, Medical Faculty, Department of Pediatrics, Konya, Turkey \\ ${ }_{2}^{2}$ Abant Izzet Baysal University, Medical Faculty, Department of Pediatrics, Bolu, Turkey \\ ${ }^{3}$ Necmettin Erbakan University, Meram Medical Faculty, Department of Radiology, Konya, Turkey \\ ${ }^{4}$ Selçuk University Medical Faculty, Department of Ophtalmology, Konya, Turkey \\ 5Necmettin Erbakan University, Meram Medical Faculty, Department of Pediatrics, Konya, Turkey
}

\begin{abstract}
Summary
Severe type I plasminogen (PLG) deficiency is a rarely seen autosomal recessive disease that causes chronic inflammation in mucous membranes, primarily eye membranes. The most commonly encountered clinical manifestation is ligneous conjunctivitis. In these patients, congenital occlusive hydrocephaly may rarely be observed. In this report, we presented a newborn who had hydrocephaly in the prenatal period and presence of severe PLG deficiency was detected after birth. We found that the same disease was present in two children of the family and in the aunt of the newborn and discussed this situation. It should be kept in mind that PLG deficiency may also be present in cases with occlusive hydrocephaly and especially in newborns with the diagnosis of ligneous conjunctivitis and with familial history of ligneous conjunctivitis. (Turk Arch Ped 2013; 48: 248-250)
\end{abstract}

Key words: Congenital hydrocephaly, ligneous conjunctivitis, type I plasminogen deficiency

\section{Introduction}

Type 1 plasminogen (PLG) deficiency is rare hereditary disease with autosomal recessive inheritance. Severe PLG deficiency leads to chronic inflammation in mucous membranes including mainly the eye $(1,2,3,4,5,6,7)$. The most common clinical picture of this disease is ligneous conjunctivitis. Ligneous conjunctivitis is a rare and unusual form of chronic pseudomembraneous conjunctivitis. It usually starts in the early infancy $(1,2,5,6,7)$. In severe PLG deficiency, pseudomembraneous lesions may also develop in the other mucous membranes of the body. The main mucous membranes which are involved together with the conjunctiva include the mouth, middle ear, nasopharynx, tracheal tract, female genital tract and duodenum $(1,4,6,8)$. Congenital obstructive hydrocephaly may develop in a part of the subjects with severe PLG deficiency $(1,2,3,5,6)$. Defect in cleaning extracellular fibrin residues during wound healing after small traumas or infections is thought to be responsible in the pathogenesis of the disease $(1,2,3,7)$.
Here, we presented a newborn baby who was diagnosed with hydrocephaly in the prenatal period and who was found to have severe PLG deficiency in the postnatal period. In addition, we found that the same disease was present in the first child of the family and in two aunts and we discussed the patient in company with the literature.

\section{Case}

It was learned that hydrocephaly was found on ultrasonography prenatally in a baby who was born from a 34-year-old healthy mother by cesarean section at the 38th gestational week with a birth weight of $3600 \mathrm{~g}$ as the third child of the family. The parents were third-degree relatives (cousins). It was learned that ventriculoperitoneal shunt was placed in the first child of the family because of hydrocephaly and it was changed for two times until the age of five because of obstruction. In addition, it was reported that the first child of the family and two aunts were being followed up because of ligneous conjonctivitis. The father was healthy. On physical examination of our patient, his general status and activity was found to be well. His head circumference was found to be $34 \mathrm{~cm}(\mathrm{~N}: 31.3-35.2)$ 
and his height was found to be $46 \mathrm{~cm}$ ( $\mathrm{N}$ : 44.5-51.6). There was no anomaly in the structure of the head except for a larger than normal space of junction of the cranial bones. On ophtalmological examination, no finding was present except for mild microphtalmia and especially, there was no conjunctivitis. Examination of the other systems was normal. Regular biochemical analyses, hemogram, prothrombin time (PT), activated partial thromboplastin time (aPTT), fibrinogen and D-dimer levels were found to be normal. Serological tests for toxoplasma, rubella, cytomegalovirus, herpes simplex and others (TORCH) were found to be normal. Lumbar punction revealed normal CSF findings except for mild protein increase (96 $\mathrm{mg} / \mathrm{dL}$ ). Brain magnetic resonance imaging (MR) revealed hydrocephalus in the form of Dandy-Walker malformation (Picture 1). Since it was known that the first child and two aunts in the family had ligneous conjunctivits and decreased plasminogen levels, plasminogen activity was ordered for his baby. The plasminogen antigen level $(0,92 \mathrm{dL}$; ref: $6-25 \mathrm{mg} / \mathrm{dL}$ ) and plasminogen activity (\%19; ref: \%55-145) were found to be low and the baby was diagnosed with severe PLG deficicency. The tests ordered for the mother, father and healthy sibling of the baby revealed that they were carriers. The family tree, plasminogen antigen level and plasminogen activity of the baby is shown in Figure 1. Afterwards, the baby was started to be monitored closely and ventriculo-peritonel shunt was placed when he was 40 days old. The patient who developed no problem in the postoperative period was discharged. It was observed that ligneous conjunctivits developed also in this baby, when he was three months old.

\section{Discussion}

Plasminogen deficicency is divided into two groups: 1-) Hypoplasminogenemia or true type 1 plasminogen deficicency and 2-) Dysplasminogenemia or type 2 plasminogen deficiency. Dysplasminogenemia does not lead to a specific clinical picture. Severe PLG deficiency is characterized with disruption in cleaning extracellular fibrin during wound healing in the body $(1,3,4,6)$. As a result of this pseudomembraneous (ligneous) lesions develop in

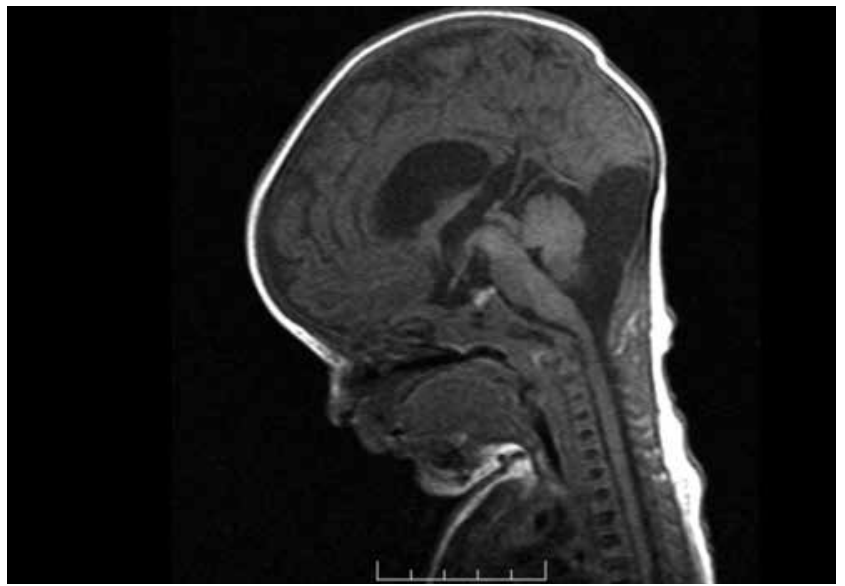

Picture 1. Hydrocephaly in the form of Dandy-Walker malformation on brain MR imaging. the mucous membranes which are involved (eye, middle ear, pharynx, upper respiratory tract, female genital organs etc.). the most commonly observed one among these is ligneous conjunctivits $(1,2,3,4,5,6,7,8,9,10)$. Ligneous conjunctivits is a rare and extraordinary form of chronic idiopathic membraneous conjunctivitis. It starts with chronic tearing in the conjunctiva. The conjunctiva gets red and pseudomembranes are formed afterwards. At the end, a thick white, yellow-white or red structure with ligneous characteristic takes the place of the normal mucosa. Infants and children constitute the most commonly affected group. Ligneous conjunctivits is usually initiated by local injuries, local or systemic infections or opthalmic surgical interventions $(1,3,4,6)$. Although plasminogen deficiency affects mainly the eyes, it is a multi-system disease which also involves the other mucous membranes in the body more or less. The mean age of onset of the first clinical findings is 9.54 months ( 3 days-61 years). The female/male ratio is $1.43 / 1(1,4)$. Ligneous conjunctivitis is observed most commonly $(81 \%)$ in the patients who are affected. Ligneous gingivitis (30\%) follows this and may result in loss of all teeth $(1,3,4,6)$. The other systems which are affected include the upper and lower respiratory tract $(20 \%)$, middle ear $(15 \%)$, female genital organs (9\%), kidneys (4\%), digestive system $(2.7 \%)$ and skin (1\%). In addition, congenital obstructive hydrocephaly may be observed in at least $12 \%$ of the patients $(1,2,3,4,5,6,7,10)$. Dandy-Walker malformation (cerebellar vermis hypoplasia and cystic enlargement in the fourth ventricle) is found in approximately half of the patients who develop congenital obstructive hydrocephaly $(1,4)$. Although the pathophysiological mechanism of obstructive hydrocephaly in plasminogen deficiency is not known clearly, it is thought that disruption of fluid circulation in the "aquaduct" region by fibrin accumulation in the ventricular system of the brain is the probable cause (6). In the literature, the number of patients with PLG deficiency who have congenital obstructive hydrocephaly is about 20 (6). One of the significant complications of ventriculoperitoneal or ventricula-atrial shunts placed in these patients is frequent obstruction and need for replacement of the shunt $(1,5,7)$.

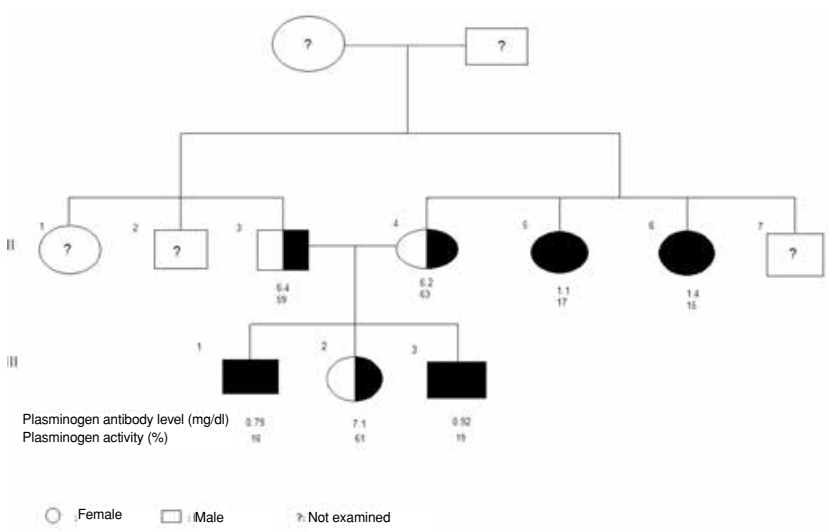

Figure 1. The family tree of the family with type 1 plasminogen deficiency. 
In our patient, the diagnosis of hydrocephaly was made in the prenatal period. It was known that the first child of the family was diagnosed with congenital hydrocephaly and the diagnosis of PLG deficiency was made after development of ligneous conjunctivitis. The ventriculo-peritoneal shunt placed in this child was obstructed for two times until the age of five. Since it was known that two aunts were followed up because of ligneous conjunctivitis, the diagnosis of our patient was confirmed by ordering plasminogen enzyme level and antibody level. Ligneous conjunctivits also developed in our patient three months later in the follow-up.

Both in homozygous patients and heterozygeous patients, plasminogen deficicency does not increase the risk of venous thrombosis even if the level of plasminogen is very low or even unmeasurable $(1,4,5,6)$. Although the reson for this is not known exactly, it is believed that the pathway of fibrinolysis which is expected to be established by way of intravascular plasmin is disrupted, but this is compensated by the increased fibrin/fibrinogen clearance mechanism by way of the other serin proteases or monocytoid cells $(4,6)$. Therefore, severe PLG deficiency mainly extravascular fibrinolysis rather than intravascular fibrinolysis. No history of thrombosis was present in our patient or in relatives of our patient who had the disease or who were carriers.

Plasminogen deficicency is transmitted by autosomal recessive inheritance and is a rare disease. It is presumed that the frequency of homozygous or combined heterozygous cases is less than $1 / 1$ million. It is known that the frequency of heterozygous subjects shows variance by geographical region. For example, it is $0.42 \%$ in Japan and $0.13 \%$ in North Germany $(1,6)$. Although the exact frequency among the Turkish people is not known, it is supposed that the rate of severe PLG deficicency is substantially high. A reason for this is the fact that the rate of consangineous marriage is high in our country. As a matter of fact, it is observed that an important part of the subjects published in the literature are Turkish (both from Turkey and from Europe) $(1,2,3,4,5,6,7,8,9)$. In our case, it was shown that the parents were first-degree cousins, the first child of the family and two aunts had the same disease and the parents were carriers. Based on these findings, it can be stated that the frequency of the disease in Turkey is substantially high, though not known exactly.

Although severe PLG deficiency is a rare cause of hydrocephaly, it should be considered especially in cases of obstructive hydrocephaly. Therefore, PLG deficiency should be suspected, if there is a familial history of hydrocephaly or ligneous conjunctivitis. Moreover, hydrocephaly may not be recognized before marked clinical findings appear in patients with ligneous conjunctivitis. Hydrocephaly may even be the first finding of PLG deficiency and ligneous conjunctivitis may occur later. It is known that plasminogen deficiency occurs more commonly in the Turkish people. Therefore, all infants with PLG deficiency should be screened in terms of hydrocephaly for early diagnosis and treatment and PLG deficiency should also be investigated in cases of obstructive hydrocephaly. In addition, it should be known that the ventriculo-peritoneal shunts used in treatment of this hydrocephaly may be obstructed frequently.

\section{References}

1. Schuster V, Hügle B, Tefs K. Plasminogen deficiency. J Thromb Haemost 2007; 5: 2315-2322.

2. Schuster V, Seidenspinner S, Müller C, Rempen A. Prenatal diagnosis in a family with severe type I plasminogen deficiency, ligneous conjunctivitis and congenital hydrocephalus. Prenat Diagn 1999; 19: 483-487.

3. Schott D, Dempfle CE, Beck P, et al. Therapy with a purified plasminogen concentrate in an infant with ligneous conjunctivitis and homozygous plasminogen deficiency. N Engl J Med 1998; 339: $1679-1686$

4. Tefs K, Gueorguieva M, Klammt J, Allen CM, Aktas D, Anlar FY, Aydogdu SD, Brown D, Ciftci E, Contarini P, Dempfle CE, Dostalek M, Eisert S, Gökbuget A, Günhan O, Hidayat AA, Hügle B, Isikoglu M, Irkec M, Joss SK, Klebe S, Kneppo C, Kurtulus I, Mehta RP, Ornek K, Schneppenheim R, Seregard S, Sweeney E, Turtschi S, Veres G, Zeitler P, Ziegler M, Schuster V. Molecular and clinical spectrum of type I plasminogen deficiency: A series of 50 patients. Blood 2006; 108: 3021-3026.

5. Aslan AT, Ozcelik U, Dogru D, et al. Congenital hydrocephalus as a rare association with ligneous conjunctivitis and type I plasminogen deficiency. Neuropediatrics 2005; 36: 108-111.

6- Ciftçi E, Ince E, Akar N, Dogru U, Tefs K, Schuster V. Ligneous conjunctivitis, hydrocephalus, hydrocele, and pulmonary involvement in a child with homozygous type I plasminogen deficiency. Eur J Pediatr 2003; 162: 462-465.

7. Schuster V, Mingers AM, Seidenspinner S, Nüssgens Z, Pukrop $\mathrm{T}$, Kreth HW. Homozygous mutations in the plasminogen gene of two unrelated girls with ligneous conjunctivitis. Blood 1997; 90: 958-966.

8. Lotan TL, Tefs K, Schuster V, Miller J, Manaligod J, Filstead A, Yamada SD, Krausz T. Inherited plasminogen deficiency presenting as ligneous vaginitis: a case report with molecular correlation and review of the literature. Hum Pathol 2007; 38 : 1569-1575.

9. Kraft J, Lieb W, Zeitler P, Schuster V. Ligneous conjunctivitis in a girl with severe type I plasminogen deficiency. Graefes Arch Clin Exp Ophthalmol 2000; 238: 797-800.

10. Suzuki T, Ikewaki J, Iwata $H$, Ohashi $Y$, Ichinose A. The first two Japanese cases of severe type I congenital plasminogen deficiency with ligneous conjunctivitis: successful treatment with direct thrombin inhibitor and fresh plasma. Am J Hematol 2009; 84: 363-365. 